\title{
O homem duplicado, Ensaio sobre a lucidez e As intermitências da morte: (Sus)penso no mundo
}

\section{The double, Seeing and Death at intervals: suspended worldwide}

\section{Josiele Kaminski Corso-Ozelame* \\ Universidade Estadual do Oeste do Paraná}

Resumo: Os romances de José Saramago rompem com o tempo e o espaço da narrativa, como em O homem duplicado (2002), Ensaio sobre a Lucidez (2004) e As intermitências da Morte (2005), em que não encontramos a História como subsídio de criação. E sim, histórias que, conforme alguns críticos, projetam o que poderia ser em qualquer lugar/momento, estabelecendo relações entre presente e futuro particulares, isto é, o estar no mundo fica em suspenso, para que o narrador e as personagens questionem uma espécie de "estar em si”, com toda a carga de necessidades e insatisfações que isso exige. Para compreender e verificar de que maneira se dá esta mudança temática nos três romances supracitados, este texto levará em consideração as reflexões teóricas de Álvaro Cardoso Gomes (1993), Carlos Reis (1998), Hans Robert Jauss (1994), Linda Hutcheon (1991), para analisar, a partir da diegese, aspectos como, ficção, História, cotidiano, ruptura temática, recepção e valor estético.

Palavras-chave: Diegese. José Saramago. Ruptura.

\begin{abstract}
Novels of José Saramago rupture with time and space of the narrative, as it occurs in The double (2002), Seeing (2004) and Death at intervals (2005), in which is not found history as subsidy of creation. According to some critics, there are stories which project what could be anywhere, anytime, establishing relationships between individual's present and future, that is, the being in the world is suspended, so that the narrator and the characters may question a kind "to be themselves" with a whole load of needs and dissatisfactions that this requires. To understand and verify how this change occurs in the three thematic novels above, this paper will consider the theoretical reflections of Álvaro Cardoso Gomes (1993), Carlos Reis (1998), Hans Robert Jauss (1994), Linda Hutcheon (1991), to analyze, from the diegesis, aspects as: fiction, history, daily moment, themed rupture, reception and aesthetic value.
\end{abstract}

Keywords: Diegesis. José Saramago. Rupture.

\author{
* Doutora em Literatura, \\ professora do Curso de \\ Letras da Universidade \\ Estadual do Oeste do \\ Paraná - Unioeste - \\ Campus de Foz do \\ Iguaçu, PR. E-mail: \\ $<$ josicorso@gmail.com>
}




\section{Introdução}

Os romances de José Saramago merecem atenção não só devido aos laços que estabelecem entre História e Ficção, reconstruindo perspectivas de verdades, como também pela capacidade imaginativa do escritor, que, por meio de seus controversos narradores, manipula as convenções narrativas, questiona crenças e aspirações, contesta e comenta ideologias e atitudes, dialogando com os leitores. É o narrador saramaguiano quem amarra as diferentes vozes polifônicas, arranja a temporalidade da obra, promove reflexões acerca do que vê e coloca o leitor em crise - em seu estatuto onisciente, ele faz e desfaz, é feito e desfeito.

A partir de 2002, Saramago volta-se a histórias de fundo detetivesco ou de suspense, para analisar o que é e/ou projetar o que poderia ser, estabelecendo relações entre presente e futuro muito particulares. Em função dessa mudança, num primeiro momento, essas produções foram consideradas menores, por não tratarem da releitura da História como tema central. $\mathrm{O}$ estar no mundo fica em suspenso, para que o narrador e as personagens olhem para si mesmas, questionando uma espécie de "estar em si", com toda a carga de necessidades, obrigações e insatisfações que isso exige, como bem o demonstram: Tertuliano Máximo Afonso e António Claro; a Mulher do Médico e a Morte; e o Violoncelista. Embora voltados para um aspecto, digamos, mais individual, O Homem Duplicado (2002), Ensaio sobre a Lucidez (2004) e As Intermitências da Morte (2005) são romances que não deixam de trazer a marca saramaguiana, na medida em que, apesar de alterada a temática recorrente, que tinha os olhos postos no passado, as buscas e descobertas de suas personagens projetam-se para um possível futuro. Saramago experimenta a história do homem, sem marcadores temporais e espaciais. A radicação social, característica latente em seus textos - e aliada ao seu estilo particular -, leva-nos a pensar sobre o presente, dado que se insere, nesses romances, na estrutura narrativa, subvertendo tempo e espaço.

Tendo em vista os romances já mencionados, propomo-nos a refletir e compreender os motivos que levaram a crítica a considerá-los menos relevantes, com o objetivo, também, de levantar hipóteses que evidenciem tais romances como pares dos demais - ainda que sejam não-históricos, nem por isso são menos instigantes, pois conservam características reconhecidamente saramaguianas.

\section{A reescrita da História}

A literatura se faz presente, sem dúvidas, nos momentos de retomadas de abalo da ordem histórica, não somente com testemunho, mas principalmente como intervenção no desenrolar dos acontecimentos. A História de Saramago, convertida em história, nos proporciona as mais diversas 
reflexões sobre o processo de re(construção) focalizado, diretamente, na humanidade.

Não só na produção do Nobel a temática da reescrita da História é recorrente. No caso específico de José Saramago, a crítica especializada tem traçado uma linha demarcatória entre suas obras-primas - os chamados romances históricos, que partem do aspecto problematizante, mesclando personagens ficcionais e reais, numa tentativa de correção da História - e as ditas narrativas menores - denominadas por mim, universais -, em que essa problematização cede lugar a uma espécie de reflexão que transcende às questões do tempo dado. Nesses romances, o tempo ficcional saramaguiano tem sido atrelado à existência humana e relacionado à experiência social vivida, independentemente de marcos históricos.

Sobre o tempo em Saramago, a estudiosa Maria Alzira Seixo afirma que a "globalidade de seus escritos é urdida em palavras da experiência temporal do homem que se recorta num cotidiano social e atualmente emergente” (SEIXO, 1999, p. 91) - e são vários os tempos que se atravessam e entrecruzam em suas narrativas, proporcionando releituras de fatos ocorridos em outras épocas, projetando-os para a sociedade contemporânea das mais diversas maneiras, e reintegrando passado, presente e futuro.

Carlos Reis (1998) corrobora as ideias de Seixo, partindo do pressuposto de que o romancista não se ocupa da dita História - "uma grande zona de obscuridade” -, mas a toma como ponto de partida. É nesse entremeio que se situa a inquietação da reconstrução do passado, o qual, não podendo ser literalmente reconstruído, pode, em tese, ser corrigido. A suposta correção consiste em colocar alguns elementos ficcionais que façam com que o romance pareça indiscutível, como escreve Reis: "Substituir o que foi feito pelo que poderia ter sido” (REIS, 2003, p. 502). Portanto, as “incoerências” históricas são para o ficcionista uma viagem convidativa à imaginação. José Saramago, utilizando-se das “zonas obscuras” produziu romances históricos, nos quais buscava corrigir a História em função da ficção - e não o contrário.

Nesses romances, o ápice não acontece com a consagração de feitos louváveis de grandes e poderosos; são os desprivilegiados e esquecidos que transpõem barreiras para fazer parte da história. Como marca registrada da ficção portuguesa, segundo Álvaro Cardoso Gomes,

o romance português contemporâneo não só fará uso do inventário crítico da situação sócio-político-econômica portuguesa, como também fará um inventário crítico da linguagem, do modo de narrar e do compromisso do escritor com a realidade (GOMES, 1993, p. 84).

Para o estudioso, o escritor fornece um leque de possibilidades interpretativas da realidade, pois ao recriá-la faz uma projeção do 
imaginário sobre o real para "melhor desvendá-la ou mesmo para melhor transformá-la” (GOMES, 1993, p. 85).

Silva reflete sobre os possíveis limites “delineáveis - ou não - do histórico e do ficcional” (SILVA, 1999, p. 109). Para ela, Saramago, apesar de retomar as ideias antigas, as recontextualiza sob um prisma diferente, ou seja, utiliza-as (corroborando a afirmação feita por Gomes) para fazer reivindicações, indo além do resgate da História. A estudiosa observa ainda que Saramago tem a ousadia de questionar e refletir ficcionalmente por meio do seu discurso de "tempos novos e não eternos” (SILVA, 1995, p. 723). É por meio da História, mais uma vez, que o romancista toma o poder da liberdade de narrar de outra maneira os espaços vazios, fazendo a leitura do tempo histórico, em que é o "Sacrilégio que consagra a versão nova que só no espaço da ficção é cabível” (SILVA, 1995, p. 725). Assim, juntamente com o fruir imaginativo, Saramago fantasia a História, transgredindo os fatos, motivado por sua sensibilidade perante o passado que conhece, e disposto a oportunizar aos leitores uma visão histórica inquietante, pois todo discurso, mesmo como fingimento, sempre possibilita, favorece ou impede interpretações.

A História, portanto, não é mais vista como fonte incontestável de verdade absoluta, porque ela propõe uma releitura dos documentos armazenados. O historiador contemporâneo, imerso na multiplicidade e na diferença, nega-se a deixar para sempre calados aqueles que foram deixados de lado pela História. Então, “faz falar diferentemente os documentos, indaga-os em seus silêncios, em suas ausências, e em suas falhas” (SILVA, 1999, p. 111). O romancista tem o poder de modificar a História, pois, em se tratando de ficção, ele não tem comprometimento com a "veracidade" que os fatos registraram.

É feita, portanto, uma leitura possível da História dos homens, e o passado não serve mais como modelo fiel do presente; pelo contrário, o momento presente reavalia o passado, até porque este é repleto de lacunas duvidosas. Por meio dessas “incertezas” é que o escritor, utilizando-se da ficção, ultrapassa a fronteira do imaginário. Ele tem a possibilidade de fornecer ao leitor o "retrato bruto da alienação ou mesmo o vazio que o cerca” (GOMES, 1993, p. 121). Beatriz Berrini (1999) afirma sobre a construção da narrativa que, quando se narra um momento histórico, o autor precisa ir muito além das características do que aconteceu, repetir falas da época, descrever ambientes, homens e mulheres, transcrever sentimentos e ideias. A superação de uma história fechada se dá com a capacidade imaginativa do historiador, da sua experiência e do conhecimento da sociedade e de seus homens. Assim, ele tornar-se-á além de historiador, um ficcionista.

O Leitor de História [e até certo ponto o de Ficção] tem consciência clara que de tal foi possível graças à inteligência e sensibilidade do autor, 
na sua atividade de pesquisa e interpretação, sem dúvida, mas também pela reconstituição do passado obtida pela força de sua fantasia criadora (BERRINI, 1999, p. 66).

Por meio da "fantasia criadora" é que Saramago consegue adentrar no mundo duplamente fictício de suas personagens: conhecendo o que elas pensam e sentem. Assim, Berrini destaca que é justamente por isso que "a Ficção parece-nos mais autêntica que a realidade. Por tal motivo também, somente acreditamos que a História é verdadeira, quando ela alcança expressar a profundidade interior peculiar ao ser humano” (BERRINI, 1999, p.66).

O historiador, para conseguir reconstruir o passado, algumas vezes também tem de ter um pouco de romancista, já o ficcionista, como está enraizado numa determinada época e num determinado contexto, pode fazer pesquisas de campo, informar-se antes de fazer a redação de seu texto. Nesse sentido, Walter Benjamin observa que o cronista "narra os acontecimentos, sem distinguir entre os grandes e os pequenos, leva em conta a verdade de que nada do que um dia aconteceu, pode ser considerado perdido para a história” (BENJAMIN, 1996, p. 223).

É a partir de Todos os Nomes que as narrativas de Saramago apontam muito mais para uma projeção de futuro, preocupadas quase que, exclusivamente, com o homem do cotidiano. Não busca mais falar sobre Portugal (como, por exemplo, em O Ano da Morte de Ricardo Reis, História do Cerco de Lisboa, A Jangada de Pedra), entretanto universaliza seu discurso, para que cada leitor possa tornar-se personagem da narrativa em seu tempo presente, deparando-se com seus medos, angústias e dificuldades perante a vida. As referências de identificação tempo/espaço em Manual de Pintura e Caligrafia, Ensaio sobre a Cegueira e Todos os Nomes se revelam enfraquecidos, fazendo deles um local de limpidez, no qual o leitor poderá ver seu reflexo enquanto cidadão do mundo, na sua participação da construção da história cotidiana.

Analisando a transformação temática ocorrida em sua obra, Saramago apesar de recusar a classificação de escritor pós-moderno, está inserido em uma modernidade tardia. Ainda que alguns romances sejam classificados como históricos, Andrea do Roccio Souto (2005) indica que, se se voltar os olhos para a questão da identidade e do deslocamento do sujeito discursivo em confronto com os registros históricos, percebe-se que sua escritura aponta na direção da metaficção historiográfica, desconstruindo um discurso paradigmático. Isso, conforme Linda Hutcheon, caracterizaria a cultura pós-moderna que

usa e abusa das convenções do discurso. Ela sabe que não pode escapar ao envolvimento com as tendências [... ] de seu tempo. Não há saída. Tudo o que ela pode fazer é questionar a partir de dentro (HUTCHEON, 1991, p. 15). 
Portanto, a ficção pós-moderna, não tem por objetivo relatar uma verdade, mas sim, contestar o fundamento da legitimidade na pretensão do relato da verdade. Os fatos existem, a partir da pergunta que fazemos a eles.

\section{Universalização temática: um atalho no caminho}

A reflexão sobre a ética, a razão e a problemática do humano torna-se latente também em O Homem Duplicado, em Ensaio sobre a Lucidez e em As Intermitências da Morte, que igualmente abandonam a retomada da História para abordarem relações do cotidiano do homem com possíveis situações e acontecimentos futuros inseridos num "caos" moderno. No termo científico da palavra, não há questões relacionadas à História nos romances Ensaio sobre a Cegueira e Todos os Nomes, contudo foram considerados por estudiosos como narrativas de grande relevância. Já com relação a O Homem Duplicado, Ensaio sobre a Lucidez e As Intermitências da Morte, o escritor (ainda em vida) recebeu duras críticas por abandonar a antiga temática, e essas narrativas foram consideradas “menores”, embora mantivessem a presença do narrador demiurgo e onisciente, fundamental na história que é contada e também nas tematizações das facetas utilizadas na ficção de Saramago, capazes de desnortear o universo e desequilibrar o estado presente aparentemente normal.

A ruptura da temática usual, e consequente desprestígio (efêmero) junto à crítica, deu-se, especialmente, com a publicação de $\mathrm{O} H$ Homem Duplicado, romance com características policialescas que, a cada (re)leitura, torna-se mais complexo e profundo no clima de mistério e incertezas que busca compor, bem como no que se refere à curiosidade pelo desconhecido. Aqui, o enredo cruza as fronteiras do mundo cotidiano e Tertuliano Máximo Afonso descobre que tem um duplo. No desdobrar da narrativa, a personagem passa a desempenhar o papel de duplo de seu próprio duplo, desencadeando o temor mais comum do homem moderno: não saber ao certo quem é. Para Adriano Schwartz (2005), este romance é de complexa inserção na obra de Saramago, mas observa que em relação à estrutura e à temática já é possível perceber aspectos fundamentais do Português.

As particularidades do discurso literário, que trazem à tona novas propostas inacreditáveis, muitas vezes, impossíveis de acontecer, só são possíveis através do discurso ficcional, algumas vezes encarado de maneira absurda ou até mesmo incompreensível. Dessa forma, a atemporalidade da obra propõe um universo aberto em que o leitor pode descobrir inúmeras significações. Para Umberto Eco, “qualquer texto, que pretende afirmar algo unívoco, é um universo abortado, isto é, a obra de um demiurgo desastrado (que tentou dizer 'isso é isso' e fez surgir, ao contrário, uma cadeia interrupta de transferências, em que ‘isso não é isso)” (ECO,1993, p. 45). 
Portanto, temos um romance que a partir da consciência individual, projeta-se para o universal. Nesse sentido, Shirley de Souza Gomes Carreira (2004) afirma que Saramago volta sua atenção para atualidade, enfocando a massificação dos seres humanos. Por meio de absurdas coincidências, encontros e desencontros, as personagens deste romance, experimentam angústias, certezas, incertezas do mundo social. Portanto, a partir dos estudos de Terry Eagleton (1998), podemos dizer que Saramago observa o mundo conjunto de culturas instáveis e desunificadas que destroem a verdade das relações e das identidades. Nesse sentido, Carreira assegura que

a crítica encontra, na leitura que faz da obra, a destruição do caráter, a reflexão sobre a identidade, as difíceis relações em sociedade, entendendo, com isso, que Saramago, escritor das mazelas individuais e coletivas, oferece, de novo, um romance dolorido. Aborda ainda o inusitado da obra no que se refere à escolha de nomes para as personagens, induzindo o leitor a questionar-se sobre a importância e significação destes nomes no contexto da narrativa (CARREIRA, 2004, p. 112).

Rita de Cássia da Silva Ferreira (2004) observa que o escritor, por meio da reflexão, busca resposta na profundidade dos seres humanos. Para ela, os romances exercem no leitor o fascínio pela leitura. Assegura que

se os romances da última fase são considerados menos avassaladores e de mais fácil aproximação, o próprio autor sugere uma investigação a respeito desta preferência por parte dos leitores, e ainda oferece sua tese que nada tem a ver com aspecto formal "menos denso" dos textos (FERREIRA, 2004, p.11).

O ser e o estar no mundo são aspectos capazes de desencadear no indivíduo as crises de identidade, as quais, para Stuart Hall (1998), são vistas como parte de um processo amplo de mudança, que não somente deslocam estruturas e processos centrais da sociedade, mas também abalam os aspectos de referência em que os indivíduos se baseavam para se sentirem num mundo social estável. Apesar de, nestes romances, a história não servir de alavanca, outros temas se fazem presentes e são conduzidos pelo narrador, ironizando a própria ironia, interferindo no labor da escritura, conversando com o leitor, julgando as personagens. Essas temáticas frequentemente levam o leitor a relacionar o texto em questão com os outros romances, os históricos, que, apesar de cronologicamente distantes, permitem a reflexão acerca de questões existenciais, políticas, governamentais e religiosas.

A questão da identidade, para ela, vai muito além dos limites da criação literária e invade o espaço padronizado do conhecimento, fazendo que nos transportemos para o universo do enredo, identificando-nos com os seres de papel que o escritor criou, conquistando o leitor por meio da experiência suprema. 
O Ensaio sobre a Lucidez seguiu-se à trama do duplo, e foi recebido como sequência do Ensaio sobre a Cegueira, pois além de outros aspectos, toma emprestado algumas de suas personagens. Mais uma vez, o leitor é surpreendido por uma situação que, até então, seria impossível de acontecer: no dia das eleições, a maioria da população vota em branco, desencadeando consequências caóticas em termos sociais e políticos. $\mathrm{O}$ romance parece indicar que devido à lucidez (ou à sua falta), um único indivíduo pode mudar completamente o destino da sociedade.

Desta vez, a crítica direta se faz aos governantes e aos cidadãos, não de Portugal, nem do Brasil, nem mesmo de qualquer outro lugar. A narrativa não tem espaço definido mais uma vez, portanto, novamente, ela diz respeito a todos os possíveis lugares habitados em que a população tem o direito ao voto para eleger seus governantes. Saramago desconstrói o contexto típico de lugar, conferindo ao homem uma identidade, o meio em que vive e o contexto histórico. A referência espaço/tempo neste romance é imprecisa e aqui o texto funciona como um espelho, no qual o leitor pode mirar-se e refletir sobre seu papel enquanto cidadão do mundo.

Retomando as reflexões de Eagleton (1998), é necessário mencionar que pós-modernismo surge justamente destes aspectos, do descrédito nas forças políticas, esgotamento das ideologias sociais, do tratamento da cultura como mercadoria. Muitas vezes, todos esses aspectos passam despercebidos pela sociedade, mas é certo que, eles determinam nossa existência e o destino das nações. Nesse sentido, argumenta Carreira que

A descrença da capacidade de intervenção das massas tem levado o homem a incorrer no erro da alienação. A ignorância dos assuntos políticos, aliada à deformação que alguns representantes que elegemos fazem do poder que lhes conferimos constitui uma ameaça ao exercício da democracia. A preservação dos direitos do homem, o exercício da liberdade, exige, em contrapartida, a responsabilidade social (CARREIRA, 2006, p. 06).

Comprometida com o social, a obra As Intermitências da Morte pode ser considerada como uma provocação ao senso comum, partindo de um “se”. No romance, quando as pessoas percebem que não mais morrerão, ironicamente, o pesadelo começa. A partir desse aspecto, o escritor levanta diversos outros problemas sociais ocasionados, no caso de, repentinamente, as pessoas pararem de morrer. Saramago enfoca as instituições de poder do país, como o Rei (e seus subordinados ministros) e a Igreja. Além deles, surgem também outras que estariam relacionadas a essa problemática, como as seguradoras, os cemitérios, a máfia (que vai “auxiliar” na morte daqueles que não conseguem morrer, criando esquemas de corrupção). Embora vista como uma "não genialidade” do escritor, foi julgada como uma narrativa óbvia e sem surpresas. Schwartz, a respeito da recepção dos últimos romances saramaguianos, afirma que "Comenta-se muito, entre os 
críticos do português, o fato de que, com algumas exceções, as suas narrativas não terminam tão bem quanto poderiam” (SCHWARTZ, 2005, p. 16).

Entretanto, o próprio crítico, ao finalizar o seu comentário a respeito de As Intermitências da Morte, enfatiza: “A conclusão do livro, contudo, se não redime o conjunto, mostra-se à altura do único escritor de língua portuguesa a conquistar o Prêmio Nobel de Literatura” (SCHWARTZ, 2005, p. 16). O romance é finalizado com maestria, quando Saramago se vale da frase inicial da narrativa para concluí-la:

Saiu para a cozinha, acendeu um fósforo, um fósforo humilde, ela que poderia desfazer o papel com o olhar, reduzi-lo a uma impalpável poeira, ela que poderia pegar-lhe fogo só com um contacto dos dedos, e era um simples fósforo, o fósforo comum, o fósforo de todos os dias, que fazia arder a carta da morte, essa que só a morte podia destruir. Não ficaram cinzas. A morte voltou para a cama, abraçou-se ao homem e, sem compreender o que lhe estava a suceder, ela que nunca dormia, sentiu que o sono lhe fazia descair suavemente as pálpebras. No dia seguinte ninguém morreu (SARAMAGO, 2005, p. 207).

Neste romance, Saramago não intensifica somente a temática da morte, mas sim faz uma afirmação sobre a importância da vida; que recusa e integra a morte de uma maneira paradoxal. Também opta pelo anonimato das personagens e lugares, ou seja, desta forma ele universaliza, mais uma vez, a experiência, abrangendo a todas as pessoas e a todos os lugares.

Talvez os escudos utilizados na recepção e análise desses romances dificultem que uma leitura crítica seja feita sem "pré-conceitos” estabelecidos a respeito daquilo que se espera ler. A reflexão abusiva do cotidiano, a confrontação dos princípios, a subversão de situações e as várias interrogações promovidas pelo escritor inserem-no na esteira da pós-modernidade. Considerando que “se dizer 'pós-modernista' não significa unicamente que você abandonou de vez o modernismo, mas que o percorreu à exaustão até atingir uma posição ainda profundamente marcada por ele” (EAGLETON, 1998, p. 08). Nessa perspectiva, Saramago entretece histórias desconstruindo a moral e o valor.

Para Hans Robert Jauss, em A História da Literatura como Provocação à Teoria Literária, “a maneira pela qual uma obra literária, no momento histórico de sua aparição, atende, supera, decepciona ou contraria as expectativas de seu público inicial oferece-nos claramente um critério para a determinação de seu valor estético” (JAUSS, 1994, p. 31). Saramago não reduz a distância entre o horizonte de expectativa e a obra, mantendo, assim, a qualidade de seus romances e evitando que se aproximem da “esfera da arte culinária ou ligeira” (JAUSS, 1994, p. 32), ou seja, aquelas que não exigem a mudança de horizonte do leitor, apenas atendem a suas expectativas básicas. Ora, esse não é o caso desses romances de Saramago. A propósito, nesse sentido, é de relevância ressaltar a relação entre o 
público e a literatura: cada obra possui seu público específico, histórica e sociologicamente definível, cada escritor depende do meio, das ideologias e das concepções de seu público, ou da pressuposição de um livro que exprima o que o público espera e revele sua própria imagem.

Nesse sentido, a obra literária não se apresenta como novidade absoluta num espaço vazio, mas por avisos, sinais visíveis e invisíveis, que predispõem o seu público a recebê-la. Ela desperta lembranças do já lido, expectativas quanto a meio e fim, determinada postura emocional, horizonte geral da compreensão, interpretação e gosto dos diversos leitores - ou camadas de leitores. Isso porque algumas obras, por convenção do gênero, estilo ou forma, evocam um prévio horizonte de expectativas em seus leitores, o qual pode ser possivelmente alterado com o procedimento da leitura. Percebemos esses “avisos” nas obras de Saramago, pois mesmo nos romances de temática histórica está presente, constantemente, a preocupação do escritor com o homem e suas relações político-sociais, aspecto que se estende também em nosso corpus análise.

A interpretação é necessária à medida que o texto é lido, tornando-se um elemento de compreensão. Ela não deve apenas desvendar o sentido do texto aos leitores, mas revelar, assim, as condições de possíveis efeitos. Na verdade, a leitura antecede aos atos interpretativos, pois é no processo da leitura que se dá a interação entre a estrutura da obra e aquele que a recebe. Apenas com a leitura, a obra se constituirá em algo na consciência do leitor.

Nessa perspectiva, as diferentes temáticas dos romances do escritor surgem não para contrariar ou substituir os tópicos históricos, mas para propor uma nova percepção da vida social, atualizando a relação entre a literatura e o leitor. O romancista, da mesma forma como propõe nas outras obras, promove a reflexão sobre a política, a moral, a ética, ou seja, ele coloca em xeque uma futura realidade, a partir de nosso cotidiano, de nossos valores, crenças e cultura social. Para Saramago, em declaração dada em entrevista a Carlos Reis (1998), seus livros expressam coisas fundamentais de caráter político (ou não), um conjunto de dúvidas, inquietações e interrogações que o acompanham, como cidadão, como pessoa, diante do tempo, da morte, do amor e da ideia de Deus (existente ou não).

Percebemos que, mais do que o retorno a um tempo histórico, o que vale também não é simplesmente o tempo presente, mas, sobretudo, o tempo do narrador. O ritmo na narrativa é imposto por essa voz, frente ao conflito e à diegese enfocados, e, por extensão, o tempo em primeiro plano é o tempo desse narrador, que se cola ao pano de fundo e ao tempo das personagens. É ele que submerge o pensamento do leitor e das personagens. Mistura-se, rememora fatos passados e os antecipa por meio de uma grande carga de alegorias e metáforas, elaborando uma obra aberta. Na esteira de fazer com que o leitor participe e questione a respeito da ação da narrativa, 
é possível ao leitor elaborar várias associações temáticas e temporais sobre as personagens e o enredo. $\mathrm{O}$ estranhamento é causado pelo discurso que vai muito além do que está escrito, pois carrega uma outra história paralela que não lê apenas a dimensão factual.

Essa manobra do ritmo e do tempo, articulados às personagens, ao espaço e à trama, fazem das obras saramaguianas textos verossímeis e convincentes. Em Saramago, a "realidade fora do real" situa-se no "intervalar" em que, como ele mesmo diz em Manual de Pintura e Caligrafia, se configura na ideia de que “o tempo é este papel em que escrevo”.

Nessa perspectiva, a partir das reflexões de Iser (2002b), podemos dizer que o texto de Saramago é uma tematização do mundo. Como não há uma forma pronta, um modelo dado, para que aconteça o ato criador é preciso que seja imposto a ele algo a ser implantado. Isso não significa imitar o que já está estruturalmente organizado, a intenção é decompor. Tendo como início a decomposição, há uma seleção de elementos a cada texto ficcional que transgride os limites, na medida em que são acolhidos pelo texto. Afirma Iser, que "os elementos contextuais que o texto integra não são em si fictícios, apenas a seleção é um ato de fingir pelo qual os sistemas, como campos de referências, são entre si delimitados, pois suas fronteiras são transgredidas” (ISER, 2002a, p. 961). Assim, o texto transgride limites,

como um ato de fingir, a seleção encontra sua correspondência intratextual na combinação dos elementos textuais, que abrange tanto a combinabilidade do significado verbal, o mundo introduzido no texto, quanto aos esquemas responsáveis pela organização dos personagens e suas ações. A combinação é um ato de fingir por possuir a mesma caracterização básica: ser transgressão de limites (ISER, 2002a, p. 963).

A problemática da humanidade e o desconcerto do homem se fazem presentes em praticamente todos os romances de Saramago. Via de regra, esse desconforto de estar no mundo é retratado por crises identitárias, e a narrativa do eu é construída a partir da relação que estabelece entre autor, narrador, personagens e leitores, espaço em que se entrecruzam múltiplas identidades possíveis. Dessa maneira, na construção literária que foge ao lugar-comum, Saramago atrai o leitor, divaga e reflete acerca de conteúdos profundos, explora fatos de denúncia, de insatisfação social, a história passada ou presente e aborda problemáticas universais. Maria Alzira Seixo alega que

José Saramago é, decerto, um escritor de ideias, é um escritor de representação e reconstrução da realidade, preocupado com o mundo efetivo e, embora sem ilusões nem crenças [...] é um pensador otimista e de fato construtivo: há uma lição em seus livros, embora raramente explícita [...] enriquecida pela ambiguidade (SEIXO, 1999, p. 95-96). 
Levando em consideração que o abandono do discurso histórico em Saramago o tenha situado afastado do centro, e que os limites de margem e de fronteira são muito próximos, pensar em uma literatura de margem significa pensar em tudo o que escapa ao centro, situado num lugar distante das margens. Categorizando os romances de temática histórica como centro e as últimas produções como margem, não seria possível afirmar que o centro é superior às margens, pois esse par centro e margem só existe, e só tem relevância, se levado em conta o quadro de margem e fronteira. Sobre esses aspectos, Iser nos esclarece que quando as obras estão intimamente ligadas às orientações de costume do leitor, as novas obras surgem ricas em rupturas e consistência, mas isso não significa que elas sejam mal concebidas. O que ocorre é que essas rupturas com o tradicional dificultam sua apreensão. Nesse sentido

Esse estabelecimento é ligado às orientações habituais do leitor. Daí deriva que muitas obras modernas sejam tão ricas em rupturas de consistência, e não porque sejam todas mal concebidas, mas sim porque tais rupturas dificultam o estabelecimento de consistência necessário para sua apreensão. A função comunicativa dessas rupturas é provocar o fracasso das orientações habituais e revelar sua inadequação (ISER, 1996, p. 47).

\section{Considerações finais}

Podemos observar nos romances de Saramago recorrentes temáticas que ocorrem em maior ou menor grau, como a questão identitária, ora coletiva, ora individual, articulando intervenções por meio das sugestões do narrador e sua interação com as personagens do romance. Onisciente e intruso, o narrador dá a entender ao leitor que é ele quem comanda a narrativa. No diálogo estabelecido, instaura, não raras vezes, a dificuldade de distinguir-se entre a voz do narrador e a voz das personagens, as quais se cruzam, mesclam e complementam, sempre com ironia e humor. O narrador saramaguiano, que não só conjetura, mas também emite juízos, proporciona reflexão do real inserindo o leitor no jogo literário, brincando com horizonte de expectativas que seus romances acarretam.

Isso porque, segundo Souto, “as histórias saramaguianas se tecem sempre puxando o fio de romances anteriores, descrevendo uma profícua autotextualidade” (SOUTO, 2005, p. 48). Ora, não se nega a supremacia dos romances históricos de Saramago, mas não se pode fechar os olhos para as diferentes abordagens temáticas do escritor. Seu estilo inconfundível evoca uma realidade impossível, nula de acontecer (embora não metaforicamente), mas que, ao ser exposta, fragiliza os homens por meio da morte, das incertezas, do caos, do não-saber. Em seus romances, mesmo que não nomeie personagens e lugares, o escritor chama a atenção do leitor por seus temas universais, fazendo com que uma única leitura seja insuficiente e tornando-os impossíveis de serem lidos de uma única forma, o 
que propicia que Saramago continue sendo um gênio da literatura atual, na medida em que mescla realidade, ficção e clássico, e cujos livros, traduzidos em vários idiomas, sejam lidos por pessoas dos mais distintos lugares e idades.

\section{Referências}

BENJAMIN, W. Sobre o conceito da história. In.: Magia e técnica, arte e política: ensaios sobre literatura e arte da cultura. São Paulo: Brasiliense, 1996. p. 222-232.

BERRINI, B.. O Ano da Morte de Ricardo Reis: Sugestões de Texto. In: BERRINI, Beatriz (Org.). José Saramago, uma Homenagem. São Paulo: EDUC, 1999. p. 63-84.

CARREIRA, S. S. G. A desconstrução da identidade na obra de José Saramago. Disponível on-line em: http://sincronia.cucsh.udg.mx/carreira1. htm Acesso em: 04/04/2004.

A visualidade cega: o olhar saramaguiano sobre a sociedade contemporânea. In.: Revista Eletrônica do Instituto de Humanidades. Vol. V. No. XVII. Abril - Junho, 2006.

EAGLETON, T. As Ilusões do Pós-Modernismo. Trad. Elisabeth Barbosa. Rio de Janeiro: Jorge Zahar Ed., 1998.

ECO, U. Interpretação e Superinterpretação. São Paulo: Martins Fontes, 1993.

FERREIRA, R.C.S. O homem duplicado: a subversão das identidades. 2004. 97 p. Dissertação (Mestrado em Letras Vernáculas/Literatura Portuguesa), Universidade Federal do Rio de Janeiro, Rio de Janeiro, 2004.

GOMES, Á.C. A Voz Itinerante. São Paulo: Edusp, 1993.

HALL, S. A identidade cultural na pós-modernidade. 2.ed. Rio de Janeiro: DP\&A, 1998.

HUTCHEON, L. Poética do Pós-Modernismo: História, Teoria, Ficção. Trad. Ricardo Cruz. Rio de Janeiro: Imago, 1991.

ISER, W. O Ato da Leitura: uma Teoria do Efeito Estético. Trad. Johannes Kretschmer. São Paulo: Ed. 34, 1996. v.1.

. Os atos de fingir ou o que é fictício no texto ficcional. In.: LIMA, Luiz Costa (Org.). Teoria da Literatura em suas fontes. Vol. 2. Rio de Janeiro: Civilização Brasileira, 2002a.

. Problemas da teoria da literatura atual: o imaginário e os conceitoschave da época. In.: LIMA, Luiz Costa (Org.). Teoria da Literatura em suas fontes. Vol. 2. Rio de Janeiro: Civilização Brasileira, $2002 b$. 
JAUSS, H.R. A História da Literatura como Provocação à Teoria Literária. Trad. Sérgio Tellaroli. São Paulo: Ática, 1994.

REIS, C. Diálogos com José Saramago. Lisboa: Caminho, 1998. . O conhecimento da literatura: introdução aos estudos literários. 1. ed. Porto Alegre: EDIPUCRS, 2003.

SARAMAGO, J. As Intermitências da Morte. São Paulo: Companhia das Letras, 2006.

. Ensaio sobre a Lucidez. São Paulo: Companhia das Letras, 2004.

. Manual de Pintura e Caligrafia. São Paulo: Companhia da Letras, 1992.

O Homem Duplicado. São Paulo: Companhia da Letras, 2002b.

SCHWARTZ, A. Narrador se Agiganta e Engole a Ficção. Revista Entre Livros. São Paulo, no. 08, p. 16-19, 2005.

SOUTO, A.R. Percurso Identitário: “O homem duplicado”, de José Saramago. São Miguel do Oeste: UNOESC, 2005. [Relatório de Pesquisa PIBIC/UNOESC-SMO; Bolsista: Silvia Regina Artuso de Souza]. SEIXO, M.A. Saramago e o tempo da ficção. In: TUTIKIAN, J.; CARVALHAL, T.F. (Orgs.) Literatura e História: Três Vozes de Expressão Portuguesa. Porto Alegre: UFRGS, 1999. p. 90-103.

SILVA, T.C.C. Evangelho segundo Jesus Cristo: ou a consagração do Sacrilégio. In.: Limites: anais. São Paulo: Editora da Universidade São Paulo, 1995. p. 721-728

. Na Crise do Histórico a Aura da História. In: TUTIKIAN, J.; CARVALHAL, T.F. (Orgs.) Literatura e História: Três Vozes de Expressão Portuguesa. Porto Alegre: UFRGS, 1999. p.109-118.

Recebido em: 14/04/2013

Aprovado em: 05/07/2013 